\title{
Comparison between the effects of aerobic and isometric exercises on primary dysmenorrhea
}

\author{
Asmaa M. Elbandrawy ${ }^{1 \otimes}$ and Sahar M. Elhakk ${ }^{2,3}$ \\ ${ }^{1}$ Department of Physical Therapy for Women's Health, Faculty of Physical Therapy, Cairo University, Giza, Egypt; ${ }^{2}$ Department of \\ Basic Science, Faculty of Physical Therapy, Cairo University, Giza, Egypt; and ${ }^{3}$ Department of Basic Science, Faculty of Physical \\ Therapy, Deraya University, Minia, Egypt
}

\begin{abstract}
Background: Primary dysmenorrhea is a cramping pain in the lower abdomen occurring just before or during menstruation without pelvic pathology. One of the methods used to decrease this condition's severity is exercise. Objective: The aim of this study was to compare the effects of aerobic and isometric exercises on primary dysmenorrhea. Methods: This was a randomized clinical trial that included 105 females aged 18-25 years complaining of primary dysmenorrhea. The participants were divided into three groups equal in number: (1) aerobic exercise $(n=35),(2)$ isometric exercise $(n=35)$, and (3) control group $(n=35)$. The two intervention groups performed exercises three times a week for eight weeks (two menstrual cycles). Participants were assessed using the plasma progesterone levels, visual analogue scale, and modified menstrual symptom questionnaire. Results: The within-group comparisons before and after the training program demonstrated significant differences in the aerobic exercise group regarding the visual analogue scale ( $p=.001, d=0.652$ ), plasma progesterone levels ( $p=.001, d=0.688)$, and modified menstrual symptoms questionnaire $(p=.001, d=0.607)$. Also, there were significant differences in the isometric exercise group regarding the visual analogue scale $(p=.001, d=0.633)$, plasma progesterone levels $(p=.001, d=0.502)$, and modified menstrual symptoms questionnaire ( $p=.001$, $d=0.462$ ); however, no significant differences were observed in the control group. In addition, after the end of the exercise program when compared with their corresponding values measured before intervention significant differences were observed regarding these parameters between the aerobic and control group $(p=.001)$ as well as between the isometric and control group $(p=.001)$. On the other hand, after the end of the exercise program no significant differences were observed between the aerobic and isometric groups regarding the visual analogue scale $(p=.14)$ or plasma progesterone level $(p=.14)$; however, a significant difference was observed in the modified menstrual symptoms questionnaire between these two groups $(p=.001)$ with favor to the aerobic exercise group. Conclusions: Both aerobic and isometric exercises are effective in reducing the severity of dysmenorrhea.
\end{abstract}

Keywords: aerobic exercise, isometric exercise, dysmenorrhea, modified menstrual symptoms questionnaire

\section{Introduction}

Primary dysmenorrhea is the condition referring to abnormal menstrual pain experienced by women. It is classified into two broad categories: primary dysmenorrhea (occurring without pelvic pathology) and secondary dysmenorrhea (caused by identifiable organic diseases). Primary dysmenorrhea is characterized by recurrently painful menstruation in the absence of underlying pelvic pathology (Iacovides et al., 2015). It is highly prevalent among menstruating women where a percentage ranging from $21 \%$ to $26 \%$ experience severe menstrual pain (Grandi et al., 2012). In addition to pain, women suffering from primary dysmenorrhea also experience sleep disturbance and reduced quality of life. High levels of menstrual pain are associated with significant economic burdens caused by absenteeism, reduced productivity, and two- to three-fold increased healthcare costs (Akiyama et al., 2017; Iacovides et al., 2015).
Progesterone exhibits an anti-inflammatory effect where it inhibits the release and activation of metalloproteinase during the secretory phase of the menstrual cycle. Moreover, it has an impact on the regulation and synthesis of prostaglandins and leukocytes. The pain in dysmenorrhea is attributed to the elevated level of prostaglandins in the body (Maybin \& Critchley, 2011).

Various studies are currently being performed on complementary and alternative treatments for dysmenorrhea due to high costs, complications, and contraindications of some drug therapies in addition to the accessibility and public desire for using complementary treatments. In the recent 20-30 years, regular exercise and physical activities have been introduced as effective methods for preventing and treating dysmenorrhea. It was revealed that primary dysmenorrhea patients are affected by perturbations to steroid metabolic pathways during the menstrual period and luteal regression stage (Fang et al., 2017). Exercising affects

\footnotetext{
$\triangle$ Corresponding author: Asmaa M. Elbandrawy, e-mail asma elbandrawy@yahoo.com, ORCID ${ }^{\circledR}$ record https://orcid.org/0000-0001-9993-7423 Article history: Received December 1 2020, Accepted June 8 2021, Published July 282021

Copyright: @ 2021 The Author(s). Published by Palacký University Olomouc. This is an open access article distributed under the terms of the Creative Commons Attribution License (https://creativecommons.org/licenses/by/4.0/), which permits unrestricted use, distribution, and reproduction in any medium, provided the original author and source are credited. This license does not cover any third-party material that may appear with permission in the article.
} 
the levels of steroid hormones in the blood circulation of women in reproductive ages (Jahromi et al., 2008).

Nowadays, exercise has become an integral part of the lifestyle of many women; it has numerous health benefits for their health; either regular or moderate exercise (Samadi et al., 2013). Exercising women show less severe dysmenorrhea and more positive effects than sedentary ones. Aerobic exercises decrease the adverse effects of dysmenorrhea on quality of life and social activities, stating that the women exercising regularly experience fewer adverse effects and physical symptoms across the menstrual cycle (Chaudhuri et al., 2013). Aerobic exercises such as pelvic tilting, walking, bicycling, and swimming are recommended by healthcare providers to be practiced by women as they could enhance blood flow, relax abdominal muscles, decrease pelvic pain, and relieve the pressure on nerve centers, pelvic organs, and the alimentary canal (de la Cerda et al., 2011; Tsai, 2016).

Isometric exercises are a subgroup of exercises during which no change in the muscle length or joint angle takes place. Isometric exercises reduce pain via their inhibitory effects of A-delta type and $\mathrm{C}$ fibers, decrease the duration of primary dysmenorrhea due to the increase in blood flow and metabolism of the uterus during exercise (Shavandi et al., 2010; Umeda et al., 2010).

In spite of the few clinical studies performed to demonstrate the effects of exercising on primary dysmenorrhea, no studies were done to compare the effects of aerobic and isometric exercises on dysmenorrhea. Hence, the present study aims to compare the effect of aerobic and isometric exercises on the prevention and treatment of dysmenorrhea.

\section{Methods}

\section{Participants}

Based on the research objectives and previous studies conducted on the same topic, considering $\alpha$ of .05 , power of $80 \%$, and variance of 1.5 , a 105 -subject sample size (35 in each group) was determined for the current study (Vaziri et al., 2015).

The participants were selected through convenience sampling and were divided into three groups using permuted-block randomization. In this study, 130 females were interviewed; 15 females refused to participate and 10 females were excluded as they were not fitting the study's inclusion criteria. Finally, this study was performed on 105 females recruited from the outpatient clinic of Gynecology at Kasr Al-Ainii University Hospital, Cairo. They were divided into three groups: (1) aerobic exercise group, (2) isometric exercise group, and (3) control group. The two intervention groups performed the defined exercises three times a week for eight weeks (two menstrual cycles).

A detailed medical history was taken from all participants to screen for other pathological conditions. All participants were informed briefly and clearly about the nature of exercises and their value for gaining their confidence and co-operation throughout the study. Written informed consent was obtained from all participants before their inclusion in the study. The study was approved by the Ethical
Committee, Faculty of Physical Therapy, Cairo University (P.T REC/013/001251-12/2018).

The eligibility criteria of this study were: being single, aged 18-25 years, having a regular menstrual cycle (28-32 days), body mass index (BMI) $19-29 \mathrm{~kg} / \mathrm{m}^{2}$, having menstruation cramps assessed by a modified questionnaire from Menstrual Symptom Questionnaire (Chesney \& Tasto, 1975) as at least 3-4 (moderate to severe). This is consistent with the guidelines from the Society of Obstetrics and Gynecologists of Canada regarding the diagnosis of primary dysmenorrhea (Burnett \& Lemyre, 2017), having no history of mental or physical diseases, having no history of joint, motion, muscle, or bone diseases which reduce the abilities to exercise, not being a professional athlete, taking no sedative medications, vitamin supplements, or mineral supplements during the three menstrual cycles before the trial.

\section{Measures \\ Visual analogue scale (VAS)}

This scale was used to indicate the pain intensity at the beginning of the study and after treatment; it is a numeric rating scale from 0 to 10 where 0 represents "no pain" and 10 represents the "worst possible pain". In this study, VAS was used to rate the pain commonly experienced by each participant before the intervention and at the end of the second menstrual cycle (Langley \& Sheppeard, 1985).

\section{Biochemical analyses}

Fasting morning blood samples $(5 \mathrm{ml})$ were taken before and after eight weeks of intervention. All testing was performed during the follicular phase of the menstrual cycle. Samples were taken by venipuncture from all participants after fasting for at least 12 hours. The plasma obtained was frozen at $-80^{\circ} \mathrm{C}$ for subsequent analysis. The plasma progesterone levels were measured using Radio Immune Assay kits (Cayman Chemical Company, Ann Arbor, MI, USA; Munro et al., 1991).

\section{Modified Menstrual Symptom Questionnaire (MSQ)}

The MSQ consists of 51 items was developed for both types of dysmenorrhea (primary and secondary). A modified questionnaire consisting of 14 questions adopted from the MSQ was used for the determination of the intensity of primary dysmenorrhea. In this questionnaire, the intensity of symptoms was scored from 1 to 5 where 1 represents no symptoms, and 5 represents very severe symptoms. It was shown that MSQ is a reliable tool (Chesney \& Tasto, 1975). MSQ was completed by all participants in the 3 groups before the intervention and at the end of the second cycle.

\section{Intervention}

\section{Aerobic exercise group (AG)}

Exercises were done over a period of 8 weeks, at 3 sessions in a week with $45 \mathrm{~min}$ for each session excluding days of menstruation. Each exercise stage included:

- Warming movements for 10 minutes (head movements and shoulder rotation, and balance). 
- Dynamic stretches in the form of walking lunges by taking a long stride and performing left/right walking and sideways lunges.

- Free active movements of both upper limbs from standing position: included abduction, adduction, flexion, extension and circumduction movements.

- Free active movements of both lower limbs from lie on a mat: included bending both knees and movements of abduction, adduction, flexion, extension and circumduction movements of both lower limbs.

- Active free movement of the trunk: included forward, backward and sideways from standing position.

The first week of training was equivalent to $60 \%$ of the maximum heart rate (220 - age) which progressively increased so that the work in the last session was $80 \%$ of the maximum heart rate.

Then, cool down exercises were performed for $10 \mathrm{~min}$ utes including slow marching, slow "V" step and "L" step, hamstring stretching, and quadriceps stretching (Chaudhuri et al., 2013; de la Cerda et al., 2011).

\section{Isometrics exercises group (IG)}

Isometrics exercises were given three times a week ( $45 \mathrm{~min}$ ) for eight weeks. Each exercise was performed five times with a five-second hold. The protocol of isometric exercises (five steps) was performed on a mat as follows:

- Each of the group participants lay on her back (supine position), extended her feet next to each other, pressed them on the mat, and held for $5 \mathrm{~s}$, then relaxed.

- Each participant lay on her back, put her feet crossed, pressed them on each other, held for $5 \mathrm{~s}$, then relaxed.

- Each participant lay on her back, bent her knees and thighs, put a pillow between the two knees, pressed her knees to each other, and held for $5 \mathrm{~s}$, then relaxed.

- Going back to the third position, each participant put her hand below her waist, pressed her waist to the ground, held for $5 \mathrm{~s}$, and then relaxed.

- Each participant lay in a supine position, bent her knees and thighs, and breathed through the nose while ensuring that the abdomen expands. Hands can also be put on the abdomen to ensure abdominal breath. Then, each participant exhaled from the mouth in a way that the abdominal muscles stick to the waist (Shavandi et al., 2010).

\section{Control group (CG)}

The control group was observed throughout the study period without intervention. They were not currently participating in a formal exercise program, and did not take any chemical or herbal drugs or supplements to prevent their dysmenorrhea during their menstrual period. Also, they did not have any lifestyle modifications.

\section{Statistical analysis}

SPSS Statistics (Version 19 for Windows; IBM, Armonk, NY, USA) was used for data analysis. Results are expressed as mean \pm standard deviation. Normal data distribution was confirmed by Kolmogorov-Smirnov test. Comparisons between groups were performed using analysis of variance
(ANOVA) followed by Bonferroni post-hoc test for paired comparison. Comparisons between variables measured pre- and post-intervention in the same group were performed using paired $t$-test. Effect sizes were calculated as partial eta-squared $\left(\eta_{p}^{2}\right)$ to estimate the meaningfulness of significant findings for between group comparisons. $\eta_{p}^{2}$ of .010 indicated a small, .059 a medium and .138 a large effect size, respectively. Cohen's $d$ was used for within group comparisons, where values of $0.20,0.50$ and 0.80 represent small, moderate, and large effect sizes (Cohen, 1988). The level of statistical significance was set at $p<.05$.

\section{Results}

\section{Physical characteristics for the study groups}

The general characteristics for participants in the groups at the baseline of the study were: AG: age $22.40 \pm 1.94$ years, BMI $23.20 \pm 1.71 \mathrm{~kg} / \mathrm{m}^{2}$; IG: age $22.37 \pm 1.87$ years, BMI $23.30 \pm 1.40 \mathrm{~kg} / \mathrm{m}^{2}$; CG: age $22.47 \pm 1.55$ years, BMI $22.90 \pm 1.46 \mathrm{~kg} / \mathrm{m}^{2}$. Comparison between all groups before intervention showed no statistically significant difference (AG vs. CG: $p=.98$, IG vs. CG: $p=.58$, AG vs. $\mathrm{IG}: p=.76)$.

\section{VAS}

The total mean score of the VAS was calculated for the three groups in the baseline as well as after the intervention. The study results indicated no significant difference among the three groups before the intervention as revealed by ANOVA test. Paired $t$-test revealed that there was a significant reduction of VAS after intervention compared to before intervention conditions in AG $(p=.001$, $d=0.652)$, and IG $(p=.001, d=0.633)$, but not in the CG $(p=.13, d=0.078)$. The three groups were compared using post-hoc test. The results showed a significant difference between the AG and CG $\left(p=.001, \eta_{p}^{2}=.532\right)$, and a significant difference between IG and CG $(p=.001$, $\left.\eta_{\mathrm{p}}^{2}=.512\right)$ concerning VAS after the intervention, however, no significant difference was observed between the aerobic and isometric exercise groups after the intervention $(p=.139$; Table 1$)$.

\section{Plasma progesterone level}

The total mean score of plasma progesterone was calculated for the three groups in the baseline as well as after the intervention. The study results indicated no significant difference among the three groups before the intervention as revealed by ANOVA test. Paired $t$-test revealed that there was a significant increase in plasma progesterone after intervention compared with before intervention in AG $(p=.001, d=0.688)$ and IG $(p=.001, d=0.502)$, but not in the CG $(p=.11, d=0.086)$. The three groups were compared using post-hoc test. The results showed a significant difference between AG and CG $\left(p=.001, \eta_{p}^{2}=.433\right)$, and significant difference between IG and CG $(p=.009$, $\left.\eta_{\mathrm{p}}^{2}=.420\right)$ concerning progesterone after the intervention, however, no significant difference was observed between the aerobic and isometric exercise groups after intervention $\left(p=.143, \eta_{\mathrm{p}}^{2}=.420 ;\right.$ Table 1$)$. 
Table 1 Result of VAS, plasma progesterone level, and MSQ in the three study groups

\begin{tabular}{|c|c|c|c|c|}
\hline & Before intervention & After intervention & $p$ & Cohen's $d$ \\
\hline \multicolumn{5}{|l|}{$\operatorname{VAS}(\mathrm{cm})$} \\
\hline Aerobic exercise & $6.67 \pm 1.06$ & $1.80 \pm 0.71^{*}$ & .001 & 0.652 \\
\hline Isometric exercise & $6.30 \pm 1.06$ & $2.13 \pm 0.63^{*}$ & .001 & 0.633 \\
\hline Control & $6.43 \pm 0.77$ & $6.20 \pm 1.16$ & .13 & 0.078 \\
\hline \multicolumn{5}{|c|}{ Plasma progesterone level $(\mathrm{ng} / \mathrm{ml})$} \\
\hline Aerobic exercise & $7.47 \pm 2.55$ & $10.95 \pm 3.16^{*}$ & .001 & 0.688 \\
\hline Isometric exercise & $7.08 \pm 3.40$ & $9.61 \pm 2.80^{*}$ & .001 & 0.502 \\
\hline Control & $7.61 \pm 2.23$ & $7.72 \pm 2.15$ & .11 & 0.086 \\
\hline \multicolumn{5}{|l|}{ MSQ } \\
\hline Aerobic exercise & $44.50 \pm 5.50$ & $27.63 \pm 3.49 * \#$ & .001 & 0.607 \\
\hline Isometric exercise & $45.07 \pm 5.39$ & $32.83 \pm 5.05^{*}$ & .001 & 0.462 \\
\hline Control & $45.13 \pm 5.85$ & $44.63 \pm 5.76$ & .21 & 0.067 \\
\hline
\end{tabular}

Note. VAS = visual analog scale; $\mathrm{MSQ}=$ Menstrual Symptom Questionnaire. *significantly different from the control group; ${ }^{*}$ significantly different from the isometric exercise group.

\section{Menstrual symptom questionnaire}

The total mean score of the menstrual symptom questionnaire was calculated for the three groups in the baseline as well as after the intervention. The study results indicated no significant difference among the three groups before the intervention as revealed by ANOVA test. However, a significant difference was observed among the study groups in this regard after the intervention. Paired $t$-test revealed that there was a significant decrease in MSQ after intervention compared with before intervention in both experimental groups (AG: $p=.001, d=0.607$; IG: $p=.001, d=0.462$ ) but not in the control group $(p=.21, d=0.067)$. The three groups were compared using a post-hoc test. The results showed a significant difference between AG and CG $\left(p=.001, \eta_{\mathrm{p}}^{2}=.632\right)$ and a significant difference between IG and CG groups $\left(p=.001, \eta_{p}^{2}=.391\right)$ concerning the menstrual symptom questionnaire. Also, there was a significant difference between AG and IG with favor to AG $(p=.001 ;$ Table 1$)$.

\section{Discussion}

Dysmenorrhea or painful menstruation is a highly common problem in women; it is regarded as one of the reasons for the absence of females from school or work. It was previously proven that regular exercising decreases the severity of primary dysmenorrhea (Shahrjerdi \& Shaych Hosaini, 2010).

The results of the current study showed that aerobic and isometric exercises affected dysmenorrhea where it decreased the pain intensity. However, aerobic exercises proved to be superior to isometric exercises in terms of reducing the total score of the menstrual symptoms questionnaire.

In the current study, an 8-week aerobic exercise program significantly improved the pain severity in primary dysmenorrhea. Previous studies revealed that exercise therapy and physical activity are correlated with reducing the pain of dysmenorrhea. The elevated premenstrual pelvic blood flow along with exercising delayed the onset of pain. During menstrual pain, exercising can result in faster transfer of wastes and prostaglandins from the uterus, which are the main cause of menstrual pain, from the uterus (Daley, 2008).

Stress is considered as the main factor in the relationship between physical training and dysmenorrhea (Mentheny \& Smith, 1989). It inhibits the pulsatile release of the folliclestimulating hormone and luteinizing hormone resulting in an impairment in follicular development. As the synthesis of progesterone is increased in the luteinized follicle following ovulation, stress-induced impairment of follicular development could potentially decrease the synthesis and release of progesterone (Kaur et al., 2014).

Moreover, stress can elevate the activity of the sympathetic system, increasing uterine muscle contraction and hence, increasing the symptoms of menstruation. Therefore, exercise can decrease the activity of the sympathetic system, leading to a decrease in the symptoms of dysmenorrhea (de la Cerda et al., 2011).

In some studies, a link between dysmenorrhea and levels of hormones such as progesterone, estrogen, and vasopressin was also revealed (Saadatabadi et al., 2010). The elevated level of prostaglandins in the body is the main reason of pain in dysmenorrhea; this elevation is attributed to the decrement in progesterone levels at the end of the luteal phase that stimulates the lubricating action of enzymes, leading to the release of arachidonic acid from phospholipids and activation of the cyclooxygenase pathway. The elevation of prostaglandins results in uterine contraction, uterine ischemia, and higher sensitivity to pain fibers, leading eventually to pelvic pain (Coco, 1999). Regular exercise decreases the level of serum aldosterone by reducing the level of renin and increasing estrogen and progesterone and thus decreases and improves physical symptoms (Haidari et al., 2011; Ortiz et al., 2015).

On the other hand, as per the fact that variation of sex hormones causes a decrement in the beta-endorphin level in the late luteal phase, we can say that aerobic exercising can elevate the beta-endorphin level, leading to an increase in the female's pain tolerance. In other words, performing aerobic exercise is effective in reducing the severity and duration of pain caused by the decrement in beta-endorphin levels in the body (Charkoudian \& Joyner, 2004; Lustyk et al., 2004). 
The impact of isometric exercises on primary dysmenorrhea was examined by Shavandi et al. (2010) in which they applied for an 8-week isometric exercise program on female students, concluding that isometric exercises such as abdominal, pelvic, and groin enhancement exercises decrease the severity and duration of dysmenorrhea as well as the rate of using drugs. Another study by Chantler et al. (2009) revealed that exercising due to the release of endorphins, relaxation, stress relief, and improved blood flow can reduce the severity and duration of dysmenorrhea. The mechanism of isometric exercising impact on dysmenorrhea is probably through strengthening pelvic muscles, facilitating bleeding, and excreting wastes containing prostaglandins that result in contraction. Moreover, increasing the proprioception and control of pelvic motions and muscular balance leads to the reduction of backache. Physical exercising increases the blood flow and metabolism in the uterus and thus, decreases the severity of dysmenorrhea.

A three-year survey found that the prevalence of dysmenorrhea was $39 \%$ in the exercise group and $61 \%$ in the control group (Golomb et al., 1998). In a study of athletes, Izzo and Labriola (1991) concluded that exercising before menarche was accompanied by higher reductions in the prevalence of dysmenorrheaand a decrease in intensity.

However, according to Blakey et al. (2010) study, which aimed to determine the relationship between primary dysmenorrhea and aerobic exercise on 654 female students, there was no significant relationship between primary dysmenorrhea and aerobic exercise. Fekr et al. (2012) conducted a study to compare the frequency of menstrual disorders among female athlete and non-athlete university students. They reported that the incidence of dysmenorrhea in non-athletes was higher than in athletes but the difference was not statistically significant.

Another study by Sehati et al. (2014) revealed a non-significant relationship between the distribution of dysmenorrhea between a female athlete and non-athlete students. They added that, that there was no relationship between the level of physical activity and the severity of dysmenorrhea. Also, according to Davaneghi et al. (2016) who investigated the impact of physical activity and diet on prevention and control of primary dysmenorrhea and consequently on the quality of life, there wasn't any correlation between participation in sports activity and the severity of primary dysmenorrhea.

These findings should be interpreted in light of several limitations as retrospective reporting of menstrual symptoms may lead to inaccurate reporting of symptoms, exercise was assessed by self-report and the possibility that participants overestimated this because of social desirability cannot be excluded and the sample comprised of university students who may be more educated and affluent than women not attending university; this may reduce the generalizability of the findings.

The limitation of our study was that the menstrual characteristics of the participants as (age of menarche, duration of pain, length of menstrual cycle, bleeding duration) were not reported in the statistical analysis.

\section{Conclusions}

Primary dysmenorrhea is a common complaint among young women. Based on the findings of this study, it can be concluded that regular aerobic and isometric exercises are effective, safe and noninvasive therapeutic modality in reducing menstrual pain and improving menstrual symptoms. On the other hand, we can do exercise in every place that does not need any cost.

\section{Acknowledgments}

The authors would like thank all the participants in this study for their cooperation.

\section{Conflict of interest}

The authors report no conflict of interest.

\section{References}

Akiyama, S., Tanaka, E., Cristeau, O., Onishi, Y., \& Osuga, Y. (2017). Evaluation of the treatment patterns and economic burden of dysmenorrhea in Japanese women, using a claims database. ClinicoEconomics and Outcomes Research, 9, 295-306. https://doi.org/10.2147/CEOR.S127760.

Blakey, H., Chisholm, C., Dear, F., Harris, B., Hartwell, R., Daley, A. J., \& Jolly, K. (2010). Is exercise associated with primary dysmenorrhoea in young women? International Journal of Obstetrics and Gynaecology, 117(2), 222-224. https:// doi.org/10.1111/j.1471-0528.2009.02220.x

Burnett, M., \& Lemyre, M. (2017). No. 345-Primary Dysmenorrhea Consensus Guideline. Journal of Obstetrics and Gynaecology Canada, 39(7), 585-595. https://doi.org/10.1016/i.jogc.2016.12.023

Chantler, I., Mitchell, D., \& Fuller, A. (2009). Diclofenac potassium attenuates dysmenorrhea and restores exercise performance in women with primary dysmenorrhea. Journal of Pain, 10(2), 191-200. https://doi.org/10.1016/i. ipain.2008.08.006

Charkoudian, N., \& Joyner, M. J. (2004). Physiologic considerations for exercise performance in women. Clinics in Chest Medicine, 25(2), 247-255. https://doi, org/10.1016/i.ccm.2004.01.001

Chaudhuri, A., Singh, A., \& Dhaliwal, L. (2013). A randomised controlled trial of exercise and hot water bottle in the management of dysmenorrhoea in school girls of Chandigarh, India. Indian Journal of Physiology and Pharmacology, 57(2), 114-122.

Chesney, M. A., \& Tasto, D. L. (1975). The development of the menstrual symptom questionnaire. Behaviour Research and Therapy, 13(4), 237-244. https:// doi.org/10.1016/0005-7967(75)90028-5

Coco, A. S. (1999). Primary dysmenorrhea. American Family Physician, 60(2), 489-496.

Cohen, J. (1988). Statistical power analysis for the behavioral sciences (2nd ed.). Lawrence Erlbaum Associates. https://doi.org/10.4324/9780203771587

Daley, A. J. (2008). Exercise and primary dysmenorrhoea: A comprehensive and critical review of the literature. Sports Medicine, 38(8), 659-670. https://doi. org/10.2165/00007256-200838080-00004

Davaneghi, S., Tarighat-Esfanjani, A., \& Dahri, M. (2016). Association of nutritional factors and physical activity with severity of primary dysmenorrheal pain. Journal of Health and Care, 18(2), 93-100.

de la Cerda, P., Cervelló, E., Cocca, A., \& Viciana, J. (2011). Effect of an aerobic training program as complementary therapy in patients with moderate depression. Perceptual and Motor Skills, 112(3), 761-769. https://doi.org/10.2466/02.15. PMS.112.3.761-769

Fang, L., Gu, C., Liu, X., Xie, J., Hou, Z., Tian, M., Yin, J., Li, A., \& Li, Y. (2017). Metabolomics study on primary dysmenorrhea patients during the luteal regression stage based on ultra performance liquid chromatography coupled with quadrupoletimeofflight mass spectrometry. Molecular Medicine Reports, 15(3), 1043-1050. https://doi.org/10.3892/mmr.2017.6116

Fekr, L. Z., Zadeh, T. A., Moghadam, J. B., \& Salehian, M. H. (2012). Comparison of disorders menstrual frequency between female athlete and non-athlete university students. European Journal of Experimental Biology, 2(4), 944-947. https://www.imedpub.com/articles/comparison-of-disorders-menstrual-frequencybetween-female-athlete-andnonathlete-university-students.pdf

Golomb, L. M., Solidum, A. A., \& Warren, M. P. (1998). Primary dysmenorrhea and physical activity. Medicine \& Science in Sports \& Exercise, 30(6), 906-909. https://doi.org/10.1097/00005768-199806000-00020

Grandi, G., Ferrari, S., Xholli, A., Cannoletta, M., Palma, F., Romani, C., Volpe, A., \& Cagnacci, A. (2012). Prevalence of menstrual pain in young women: What is dysmenorrhea? Journal of Pain Research, 5, 169-174. https://doi.org/10.2147/ JPR.S30602 
Haidari, F., Akrami, A., Sarhadi, M., \& Mohammad-Shahi, M. (2011). Prevalenta și severitatea dismenoreei primare și relația acesteia cu antropometrică parametru [Prevalence and severity of primary dysmenorrhea and its relation to anthropometric parameters]. Hayat, 17(1), 70-77. https://hayat.tums.ac.ir/ article-1-73-en.htm|

lacovides, S., Avidon, I., \& Baker, F. C. (2015). Women with dysmenorrhoea are hypersensitive to experimentally induced forearm ischaemia during painful menstruation and during the pain-free follicular phase. European Journal of Pain, 19(6), 797-804. https://doi.org/10.1002/ejp.604

Izzo, A., \& Labriola, D. (1991). Dysmenorrhoea and sports activities in adolescents. Clinical and Experimental Obstetrics \& Gynecology, 18(2), 109-116.

Jahromi, M. K., Gaeini, A., \& Rahimi, Z. (2008). Influence of a physical fitness course on menstrual cycle characteristics. Gynecological Endocrinology, 24(11), 659-662. https://doi.org/10.1080/09513590802342874

Kaur, S., Kaur, P., Shanmugam, S., \& Kaur Kang, M. (2014). To compare the effect of stretching and core strengthening exercises on primary dysmenorrhea in young females. IOSR Journal of Dental and Medical Sciences, 13(6), 22-32. https://doi.org/10.9790/0853-13652232

Langley, G. B., \& Sheppeard, H. (1985). The visual analogue scale: Its use in pain measurement. Rheumatology International, 5(4), 145-148. https://doi. org/10.1007/BF00541514

Lustyk, M. K., Widman, L., Paschane, A., \& Ecker, E. (2004). Stress, quality of life and physical activity in women with varying degrees of premenstrual symptomatology. Women \& Health, 39(3), 35-44. https://doi.org/10.1300/J013v39n03 03

Maybin, J. A., \& Critchley, H. O. D. (2011). Progesterone: A pivotal hormone at menstruation. Annals of the New York Academy of Sciences, 1221(1), 88-97. https://doi.org/10.1111/i.1749-6632.2011.05953.x

Munro, C. J., Stabenfeldt, G. H., Cragun, J. R., Addiego, L. A., Overstreet, J. W., \& Lasley, B. L. (1991). Relationship of serum estradiol and progesterone concentrations to the excretion profiles of their major urinary metabolites as measured by enzyme immunoassay and radioimmunoassay. Clinical Chemistry, 37(6), 838-844. https://doi.org/10.1093/clinchem/37.6.838

Ortiz, M. I., Cortés-Márquez, S. K., Romero-Quezada, L. C., Murguía-Cánovas, G., \& Jaramillo-Díaz, A. P. (2015). Effect of a physiotherapy program in women with primary dysmenorrhea. European Journal of Obstetrics, Gynecology, and Reproductive Biology, 194, 24-29. https://doi.org/10.1016/j.ejogrb.2015.08.008

Saadatabadi, F., Bambaichi, E., \& Esfarjani, F. (2010). Efectul antrenamentului de flexibilitate de șase săptămâni asupra dismenoreei [Effect of six weeks flexibility training on dysmenorrhea]. Journal of Isfahan Medical School, 28(109), 401-407.

Samadi, Z., Taghian, F., \& Valiani, M. (2013). The effects of 8 weeks of regular aerobic exercise on the symptoms of premenstrual syndrome in non-athlete girls. Iranian Journal of Nursing and Midwifery Research, 18(1), 14-19.

Sehati, F., Homaee, M., \& Zudfekr, L. (2014). Comparison of the prevalence of menstrual disorders (amenorrhea, oligomenorrhea, dysmenorrhea and premenstrual syndrome) female athlete and non-athlete students of Tabriz University. Iranian Journal of Obstetrics, Gynecology and Infertility, 16, 14-21. https://doi.org/10.22038/IJOGl.2013.844

Shahrjerdi, S., \& Shaych Hosaini, R. (2010). Efectul exercițiului de întindere de 8 săptămâni asupra dismenoreei primare la fetele cu vârste între 15 și 17 ani din liceul din Arak [The effect of 8 weeks stretching exercise on primary dysmenorrhea in 15-17 aged high school student girls in Arak]. Journal of Shahrekord University of Medical Sciences, 11(4), 84-91.

Shavandi, N., Taghian, F., \& Soltani, V. (2010). Efectul exercițiului izometric asupra dismenoreei primare [The effect of isometric exercise on primary dismenorrhea]. Journal of Arak University of Medical Sciences, 13(1), 71-77. https://iams. arakmu.ac.ir/article-1-472-en.htm

Tsai, S. Y. (2016). Effect of yoga exercise on premenstrual symptoms among female employees in Taiwan. International Journal of Environmental Research and Public Health, 13(7), Article 721. https://doi.org/10.3390/iierph13070721

Umeda, M., Newcomb, L. W., Ellingson, L. D., \& Koltyn, K. F. (2010). Examination of the dose-response relationship between pain perception and blood pressure elevations induced by isometric exercise in men and women. Biological Psychology, 85(1), 90-96. https://doi.org/10.1016/i.biopsycho.2010.05.008

Vaziri, F., Hoseini, A., Kamali, F., Abdali, K., Hadianfard, M., \& Sayadi, M. (2015). Comparing the effects of aerobic and stretching exercises on the intensity of primary dysmenorrhea in the students of universities of Bushehr. Journal of Family and Reproductive Health, 9(1), 23-28. 